\title{
Relation between apex cardiogram and changes in left ventricular pressure and dimension
}

\author{
A. VENCO, ${ }^{1}$ D. G. GIBSON, AND D. J. BROWN \\ From the Cardiac Department, Brompton Hospital, London
}

The relation between the apex cardiogram and changes in left ventricular pressure measured by micromanometer, and dimension measured by echocardiography, was studied in 12 normal subjects and 64 patients with heart disease. In 12 patients, the apex cardiogram was delayed with respect to simultaneous left ventricular pressure by $17 \pm 18 \mathrm{~ms}$ during the upstroke and $28 \pm 16 \mathrm{~ms}$ during the downstroke. In the normal subjects, changes in left ventricular dimension during the upstroke and downstroke of the apex cardiogram were small, amounting to $6 \pm 5$ and $21 \pm 7$ per cent total excursion, respectively. In 10 patients with mitral regurgitation, there was significant inward wall movement during the upstroke and in 10 patients with aortic regurgitation, significant outward movement during the downstroke, both reflecting valvular regurgitation. In 20 patients with ischaemic heart disease and segmental abnormalities on left ventricular angiography, apex cardiogramecho dimension relations were abnormal in all, because of inward or outward wall movement during the upstroke, increased outward movement before the ' $O$ ' point, or abnormal inward movement during the downstroke. These disturbances were displayed by constructing apex cardiogram-echo dimension loops, which appear to be a sensitive means of detecting incoordinate left ventricular contraction, analogous to those between pressure and dimension.

A limitation in the use of $\mathrm{M}$-mode echocardiography in studying left ventricular function is that wall movement is recorded from only a localized region of cavity, so that it is not possible to tell whether a change in dimension results from filling or ejection on the one hand, or from an isovolumic shape change on the other. The value of the technique would, therefore, be increased if information were simultaneously available allowing this distinction to be made, and incoordinate contraction and relaxation detected and quantified. We have previously shown that these abnormalities may lead to characteristic alterations in the time relations between left ventricular dimensions measured by echocardiography and left ventricular pressure (Gibson and Brown, 1976), particularly when a pressure-dimension loop is constructed. In the present study, we have explored the possibility of substituting the apex cardiogram for the pressure pulse in order to obtain the same information noninvasively. We have, therefore, investigated the time relations between the various phases of the

Received for publication 21 July 1976.

${ }^{1}$ Present address: Clinica Medica II, Università di Pavia, Pavia, Italy. apex cardiogram and the corresponding phases of the high-fidelity left ventricular pressure pulse and of the left ventricular dimension measured by echocardiography.

\section{Subjects}

\section{(1) TIME RELATIONS BETWEEN APEX CARDIOGRAM AND LEFT VENTRICULAR PRESSURE}

Observations were made in 12 patients with valvular heart disease or cardiomyopathy aged between 13 and 70. In all patients, left ventricular pressure was measured with a Millar micromanometer, mounted on a No. 5 catheter. Apex cardiograms were recorded simultaneously with the patient in the left semilateral position, often with the left arm raised, from the point of maximum impulse. A Cambridge Scientific Instruments transducer was used, with a $3 \mathrm{~cm}$ cup, a time constant of $4 \mathrm{~s}$ and a lower frequency limit of $0.05 \mathrm{~Hz}$. Pressure, apex cardiogram, and electrocardiogram were recorded photographically with no electrical damping, at a paper speed of 100 or $250 \mathrm{~mm} / \mathrm{s}$, using an SE 3012 or EMMA recorder (Fig. 1). 


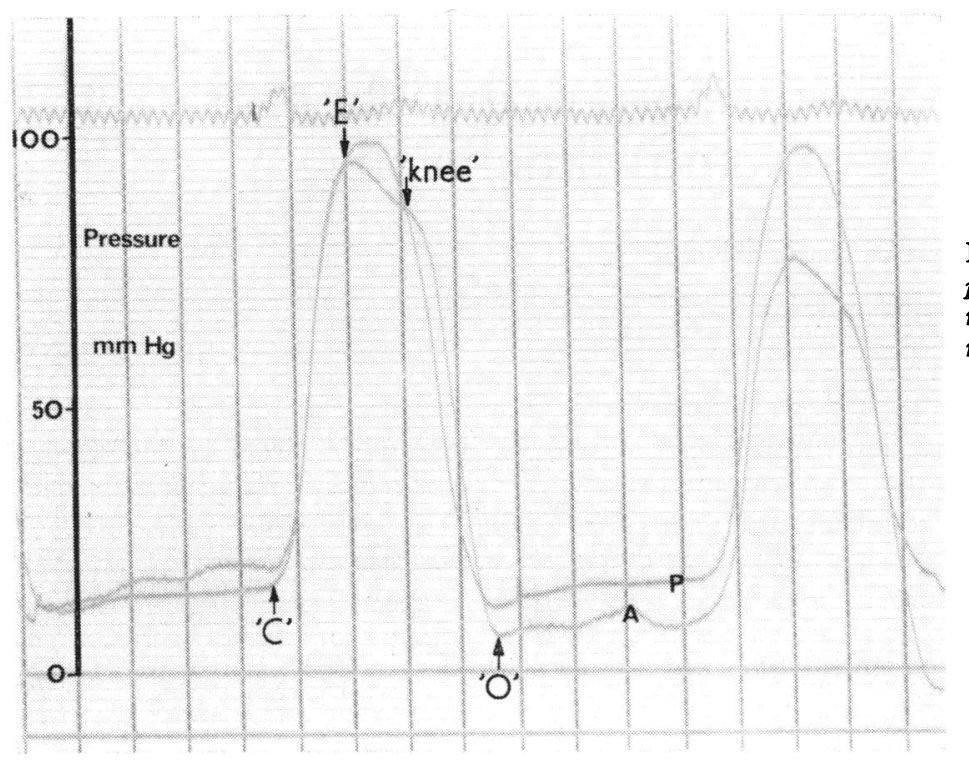

Fig. 1 Simultaneous left ventricular pressure $(P)$ and apex cardiogram $(A)$ recorded in a patient with aortic regurgitation.

\section{(2) TIME RELATIONS BETWEEN APEX CARDIOGRAM AND LEFT VENTRICULAR DIMENSION}

These studies were based on simultaneous echocardiograms of the left ventricular cavity and apex cardiograms (Fig. 2). Echocardiograms were recorded with a Smith-Kline Ekoline 20 Ultrasonoscope and either a Cambridge or a Honeywell stripchart recorder at a paper speed of $100 \mathrm{~mm} / \mathrm{s}$, using a $2 \cdot 25 \mathrm{MHz}$ transducer. Echocardiograms showed clear, continuous endocardial echoes, together with those from the mitral valve cusps, and were recorded at the same time as an apex cardiogram.

Fifty-two patients were studied who were in one of 4 groups:

\section{Group A}

Twelve normal subjects (10 male). Age range 13 to 56 years, with no clinical or haemodynamic evidence of heart disease.

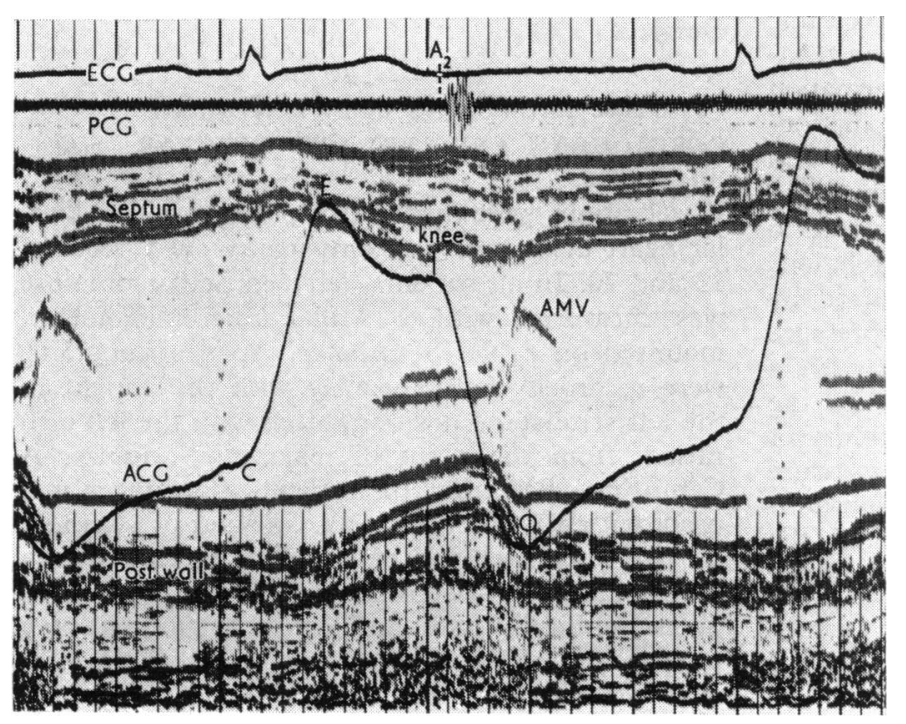

Fig. 2 Simultaneous apex cardiogram (ACG) and echocardiogram showing septum, posterior wall endocardium and epicardium, and anterior mitral valve leaflet $(A M L)$. Simultaneous electrocardiogram (ECG) and phonocardiograms (PCG) are also recorded. $A_{2}=$ aortic valve closure. 


\section{Group B}

Ten patients with aortic regurgitation. In 9, the severity of the lesion was such as to require aortic valve replacement. All were in sinus rhythm, and none had additional mitral valve disease.

\section{Group C}

Ten patients with pure mitral regurgitation, which in 6 was the result of ruptured chordae tendineae, and in 4 was rheumatic. Seven were in atrial fibrillation.

\section{Group D}

Twenty patients with significant obstructive coronary artery disease and left ventriculograms showing segmental abnormalities. None had significant mitral regurgitation.

\section{(3) DATA PROCESSING}

Echocardiograms, apex cardiograms, and pressure traces were digitised as previously described (Gibson and Brown, 1973), except that a Summagraphics digitiser ( 20 by 20 in. with 0.01 in. resolution) and a Prime 300 computer system were used. The co-ordinates of the points representing these traces were stored on disc, and used for subsequent calculations.

\section{Apex cardiogram and left ventricular pressure}

The data were further analysed to determine the correlation between the upstroke of the pressure pulse and that of the apex cardiogram (from the ' $C$ ' point to the ' $E$ ' point), and of the downstroke of the pressure and apex cardiogram (from the 'knee' to the ' $O$ ' point). The ' $C$ ' point is the onset of the upstroke, and the ' $E$ ' point the first peak or angulation of the upstroke; the 'knee' is defined as the second peak or angulation on the downstroke of the apex cardiogram, and the ' $O$ ' point as the nadir of the downstroke. The digitised apex cardiogram was displayed on a Tektronix 4010 VDU, and the two landmarks on the upstroke or downstroke identified by adjusting a cursor (Fig. 3A). The correlation between the apex cardiogram and the corresponding region of the pressure trace was then calculated. The pressure pulse was next shifted along the time axis by the computer and the correlation with the apex cardiogram calculated again. In this way, graphs of correlation between apex cardiogram and pressure over a range of time shifts were constructed and drawn on a CIL plotter using GINO-F software (Computer Aided Design Centre). From these graphs, the time shift between apex cardiogram and pressure trace, giving maximum correlation between the two, could be determined for each of the selected regions (Fig. 3B).

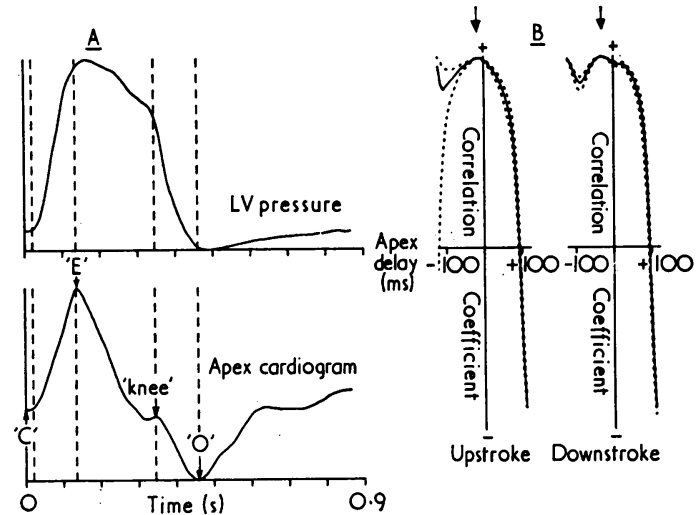

Fig. 3 (A) Digitised apex cardiogram and left ventricular pressure recordings. Vertical lines, which are defined with respect to the apex cardiogram, represent the ' $C$ ' point, ' $E$ ' point, 'knee', and ' $O$ ' point (see text). (B) Correlation between upstroke (left) and downstroke (right) of apex cardiogram and pressure trace. Peak correlation (arrows) between the two occur on the upstroke when the pressure is delayed by $13 \mathrm{~ms}(r=0.995)$ and on the downstroke when it is delayed by $33 \mathrm{~ms}(r=0.997)$. Limits representing two standard errors of the correlation coefficients are indicated (dotted lines).

\section{Apex cardiogram and left ventricular dimension}

From the digitised data plots were made of left ventricular dimension (D), rate of change of dimension $(\mathrm{dD} / \mathrm{dt})$ in $\mathrm{cm} / \mathrm{s}$, and normalised rate of change of dimension:

$$
\left(\frac{1}{\mathrm{D}} \times \frac{\mathrm{dD}}{\mathrm{dt}}=\mathrm{Vcf}\right)
$$

with the units $\mathrm{s}^{-1}$, and also the relation between the apex cardiogram and dimension, in the form of an echo dimension-apex cardiogram loop (Fig. 4). End-diastolic dimension was defined as that at the start of the $Q$ wave of the electrocardiogram of the beat in question, and was taken as zero time. Endsystolic dimension was taken as that at the time of minimum separation of the septal and posterior wall echoes. On the echo dimension-apex cardiogram loop, the following measurements were made (Fig. 5).

(i) The change in left ventricular dimension between the start of the upstroke of the apex cardiogram (' $C$ ' point) and the ' $E$ ' point, expressed as a percentage of the total excursion during the cardiac cycle.

(ii) The percentage change in left ventricular dimension between the start of the downstroke of the apex cardiogram and the minimum dimension. (iii) The percentage change in left ventricular dimension occurring between minimum dimension and the ' $O$ ' point on the apex cardiogram. 


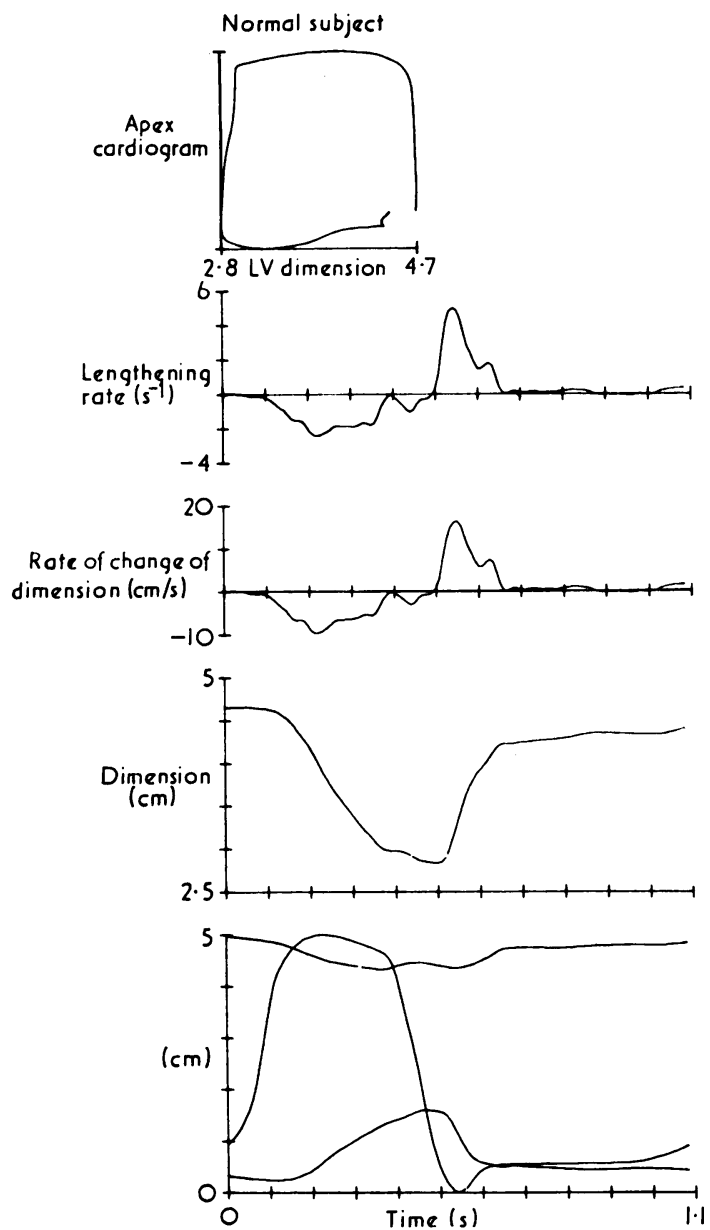

Fig. 4 Computer output of digitised apex and echocardiogram from a normal subject, representing, from below, the original data showing septum, posterior wall, and apex cardiogram; above are changes in dimension (D), rate of change of dimension (dD/dt), normalised rate of change of dimension $\left(\frac{1}{D} \times \frac{d D}{d t}\right)$ and the echo dimension-apex cardiogram loop.

Statistical analysis was by conventional $\mathrm{t}$ tests. Normal values were taken as those lying within a range of \pm 2 standard deviations of the corresponding mean value in the normal group.

\section{Results}

(1) APEX CARDIOGRAM AND LEFT VENTRICULAR PRESSURE PULSE

In all patients studied, there was a small time delay of both the upstroke and the downstroke of the apex cardiogram with respect to the left ventricular

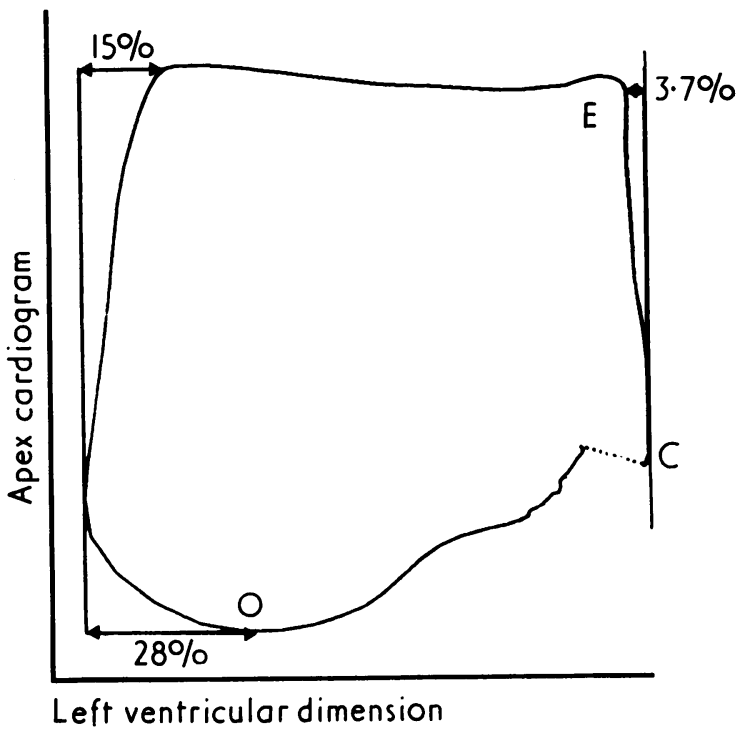

Fig. 5 Echo dimension-apex cardiogram loop from a normal subject, showing measurements made. ' $O$ ', ' $C$ ', and ' $E$ ' points are indicated, together with changes in dimension during the upstroke of the apex cardiogram, inward movement after the onset of the downstroke, and outward movement before the ' $O$ ' point. Measurements are expressed as a percentage of the overall change in dimension during the cardiac cycle.

pressure. The shift was $17 \pm 18 \mathrm{~ms}$ (mean \pm 1 standard deviation) for the upstroke and $28 \pm$ $16 \mathrm{~ms}$ for the downstroke. The magnitude of the delay in individual patients did not appear to be dependent on the nature or severity of the heart disease present.

\section{(2) APEX CARDIOGRAM AND LEFT VENTRICULAR DIMENSION \\ Normal subjects}

In all normal subjects, the upstroke of the apex cardiogram occurred at a time when there was little or no change in left ventricular dimension. This relation is apparent from direct inspection of the records, but is seen more clearly when an apex cardiogram-echo dimension loop is constructed. The maximum reduction in dimension seen during the upstroke was 15 per cent of the total excursion of wall movement, and the mean value was $6 \cdot 2 \pm$ 4.9 per cent. Left ventricular dimension did not increase at this stage of the cardiac cycle in any normal subject.

During ejection, when left ventricular dimension was falling, the shape of the apex cardiogram was variable. In the majority of cases, there was a steep descent from the ' $E$ ' point to a late systolic plateau, 
while in others there was slowing declining inward movement, and in 1 case, a late systolic bulge was observed. Because of this variability in normal subjects, no further attempt was made to study apex cardiogram-echo dimension relations at this stage of the cardiac cycle in the other groups of patients.

At the end of ejection, the apex cardiogram presents a sharp angulation downwards, the 'knee', which takes place when left ventricular dimension has almost reached a minimum. A further reduction of $7 \cdot 2 \pm 2 \cdot 9$ per cent total dimension change was found to occur in normal subjects after the time of inscription of the 'knee'. This reduction is not apparent from inspection of the original records, but can readily be measured from the apex cardiogram-echo dimension loop. The apex cardiogram continues to fall at constant dimension for a short period, but before the ' $O$ ' point is reached, a significant increase occurs, which accounts for $21 \pm 6.8$ per cent of total excursion. The mean duration of the downstroke was $120 \pm 16 \mathrm{~ms}$, and during this period septal and posterior wall echoes moved approximately parallel to one another. In 8 patients this movement was away from the anterior chest wall, in 2 towards it, and in 2 no definite direction. The ' $O$ ' point of the apex cardiogram occurred $4 \pm 10 \mathrm{~ms}$ after the time of peak rate of increase of dimension, a value not significantly different from zero, confirming the data of Prewitt et al. (1975).

\section{Aortic regurgitation}

In this group, the echo dimension-apex cardiogram loop was normal in only 2 patients. In the remainder, characteristic disturbances were present (Fig. 6). There was a mean reduction of left ventricular dimension of $13 \pm 8.3$ per cent during the upstroke of the apex cardiogram, which was greater than normal $(P<0.05)$, while the reduction in dimension after the onset of the downstroke was less $(2 \cdot 9 \pm 3 \cdot 3$ per cent), being absent altogether in 4 patients. The most prominent abnormality was a considerable increase in dimension before the ' $O$ ' point, which accounted for $43 \pm 22$ per cent of the total excursion $(P<0.01)$.

\section{Mitral regurgitation}

In all patients with mitral regurgitation, there was significant reduction in dimension during the upstroke of the apex cardiogram, amounting to $16 \pm$ 9 per cent $(P<0.05$ with respect to normal). In patients in whom the mitral regurgitation was the result of ruptured chordae tendineae, the remainder to the loop was normal (Fig. 7). On the other hand, in those in whom it was the result of rheumatic involvement, there was a very considerable increase in
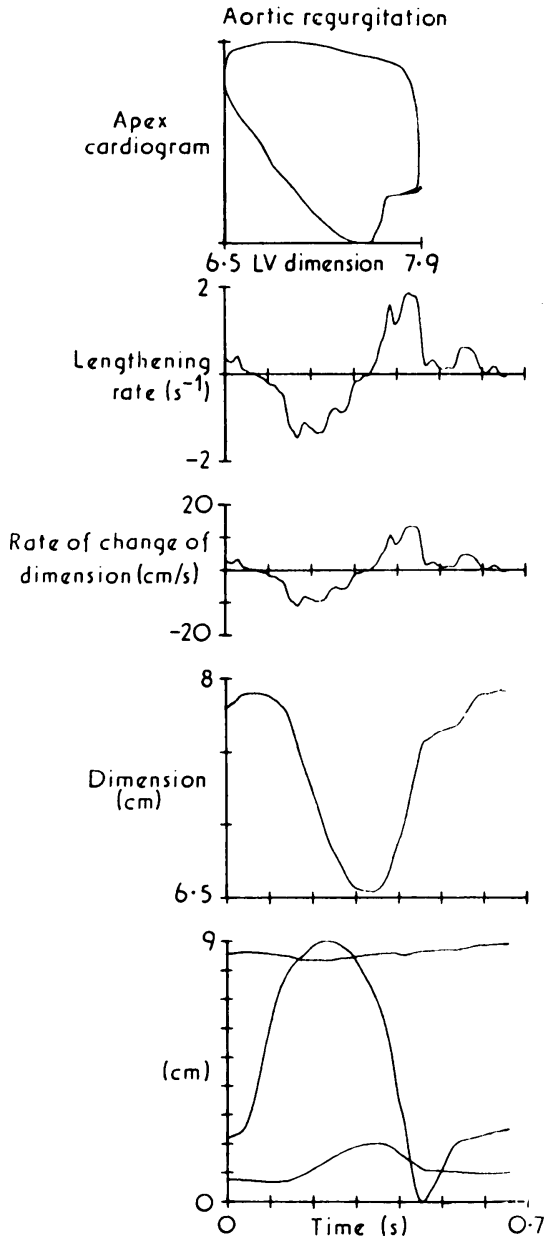

Fig. 6 Echo and apex cardiogram from a patient with aortic regurgitation. The layout is similar to that of Fig. 4. A considerable increase in dimension has taken place before the 'O' point.

dimension before the ' $O$ ' point $(55 \pm 17$ per cent $)$ $(P<0.001$ with respect to normal).

\section{Ischaemic heart disease}

A variety of disturbances was present in this group of patients, and in none were echo dimension-apex cardiogram relations completely normal. Though the mean change in dimension during the upstroke was not significantly different from normal, there was considerable scatter, with individual patients lying outside the normal range. In 6, dimension fell significantly during the upstroke by up to 39 per cent (Fig. 8) and in 6, there was an abnormal increase of up to 14 per cent of total excursion (Fig. 9). Similarly, in 5 patients, a greater 

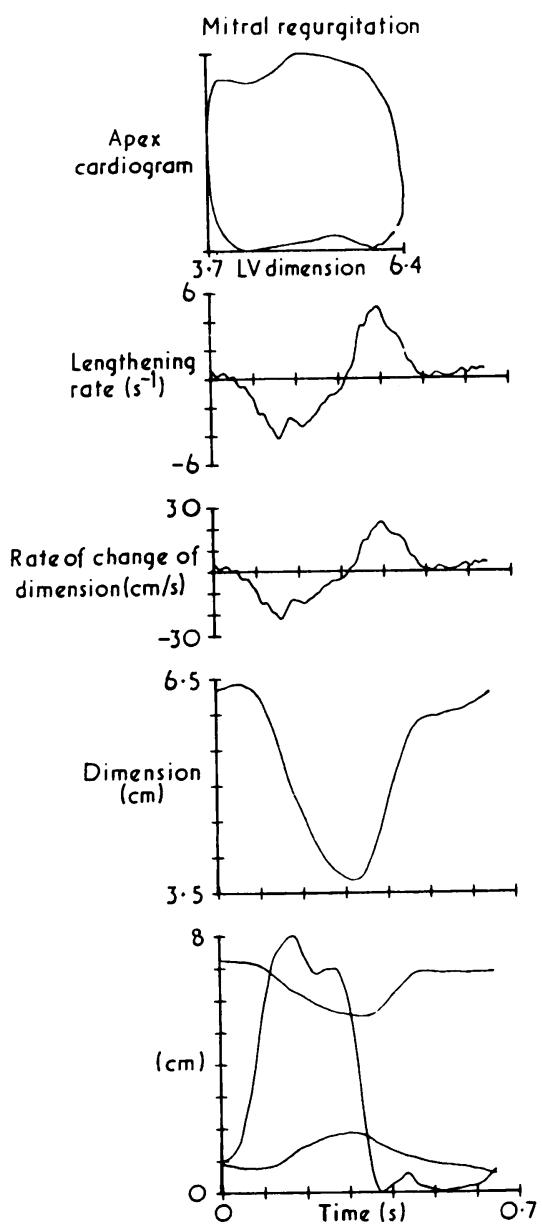

Fig. 7 Echo and apex cardiogram from a patient with mitral regurgitation. The layout is similar to that of Fig. 4. Significant inward wall movement occurs during the upstroke of the apex cardiogram.

than normal reduction in dimension occurred between the start of the downstroke and the time of minimum dimension, the maximum change observed during this period being 36 per cent. Finally, the increase in dimension before the ' $O$ ' point in the group as a whole was very abnormal, being $53 \pm$ 23 per cent $(P<0.001$ with respect to normal); values outside the normal range were recorded in 15 out of the 20 patients, of up to 100 per cent total outward movement. It has previously been shown that an abnormal isovolumic increase in left ventricular dimension may occur before mitral valve opening in patients with ischaemic heart disease (Upton, Gibson, and Brown, 1975). In 13 of the present patients, in whom simultaneous echoes from the mitral cusp and left ventricular cavity
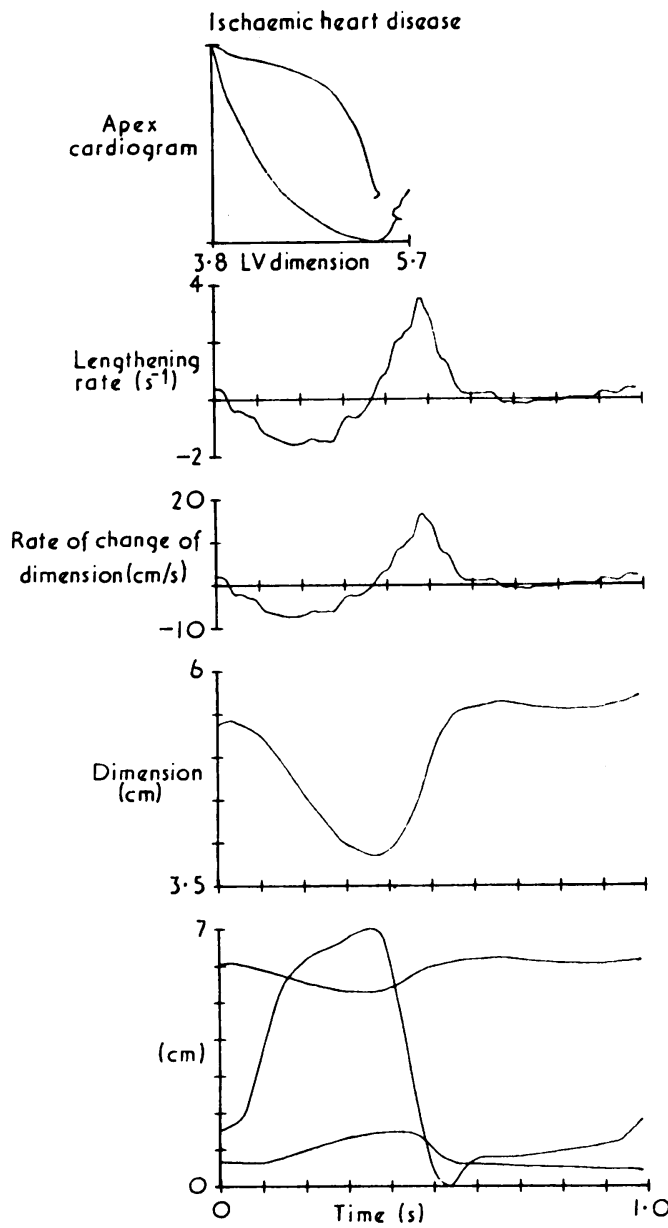

Fig. 8 Echo and apex cardiogram from a patient with ischaemic heart disease. Significant inward movement of the walls of the ventricle occurs during the upstroke of the apex cardiogram and outward movement before the ' $O$ ' point.

were recorded, the percentage change in left ventricular dimension $(x)$ before mitral valve opening was compared with that before the ' $O$ ' point ( $y$ ). This showed that there was a high correlation between the two measurements (Fig 10), given by the equation:-

$$
y=0.79 x+30, r=0.87
$$

Standard error of estimate $=9 \cdot 2$ per cent.

The value of the intercept of 30 per cent is not significantly different from the normal increase in dimension before the ' $O$ ' point.

(3) LEFT VENTRICULAR DIMENSION AND ITS RATE OF CHANGE

Mean values for left ventricular dimension and its 


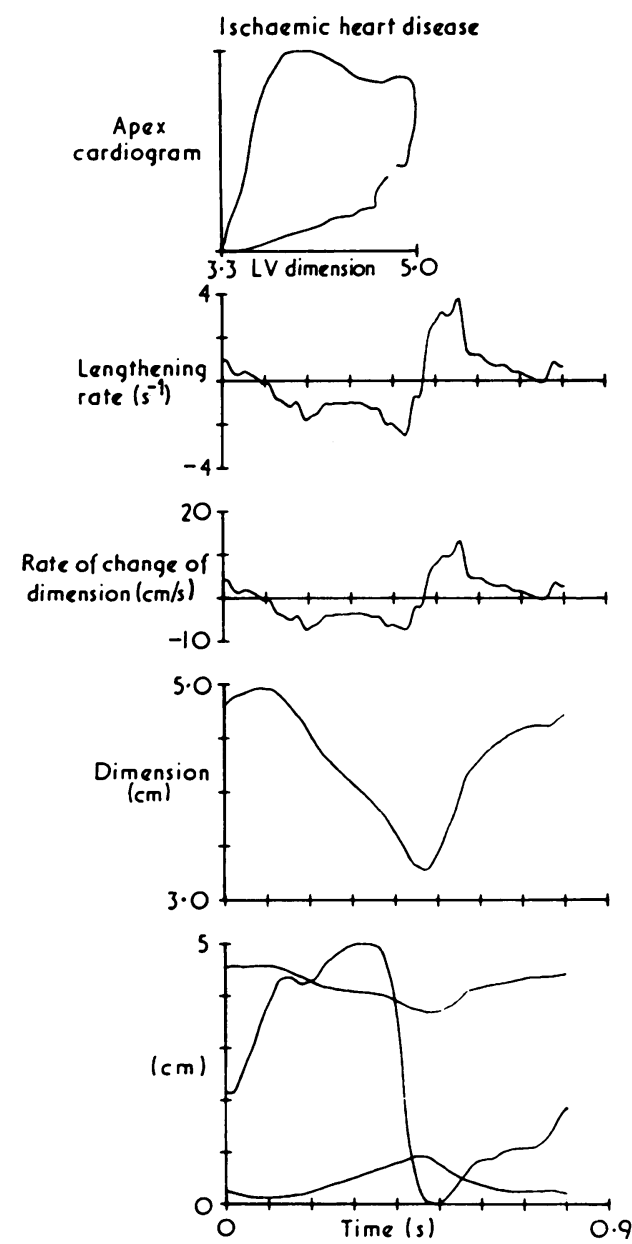

Fig. 9 Echo and apex cardiogram from a patient with ischaemic heart disease and an inferior aneurysm. There is significant outward movement before the ' $E$ ' point, and inward movement during the downstroke of the apex cardiogram, which reaches a maximum at the ' $O$ ' point.

peak rate of change during systole, expressed as peak Vcf, are given in the Table. End-systolic and end-diastolic dimensions were significantly increased with respect to normal in all patient groups studied. Peak Vof was normal in patients with mitral or aortic valve disease, but was significantly reduced in those with ischaemic heart disease.

\section{Discussion}

It has been recognised for over a century that praecordial movements of the heart are closely related in time to changes in left ventricular pressure (Chaveau and Marey, 1861). More recently, studies both in animals (Willems, de Geest, and Kesteloot, 1971)
Table Left ventricular dimensions and peak rate of change

\begin{tabular}{|c|c|c|c|}
\hline & $\begin{array}{l}\text { End-diastolic } \\
\text { dimension } \\
(\mathrm{cm})\end{array}$ & $\begin{array}{l}\text { End-systolic } \\
\text { dimension } \\
\text { (cm) }\end{array}$ & $\underset{\substack{\text { Peak } \\
\left(\mathrm{s}^{-1}\right)}}{\text { Vef }}$ \\
\hline $\begin{array}{l}\text { Normal } \\
\text { Aortic regurgitation } \\
\text { Mitral regurgitation } \\
\text { Ischaemic heart disease }\end{array}$ & $\begin{array}{l}4 \cdot 7 \pm 0 \cdot 3 \\
7 \cdot 0 \pm 0 \cdot 7^{\star \star \star} \\
6 \cdot 1 \pm 0 \cdot 8^{\star \star \star} \\
5 \cdot 4 \pm 1 \cdot 0^{\star \star}\end{array}$ & $\begin{array}{l}3 \cdot 0 \pm 0 \cdot 4 \\
4 \cdot 8 \pm 0 \cdot 8^{\star \star \star} \\
4 \cdot 0 \pm 0 \cdot 8^{\star \star} \\
4 \cdot 0 \pm 1 \cdot 1^{\star}\end{array}$ & $\begin{array}{l}2 \cdot 4 \pm 0 \cdot 3 \\
2 \cdot 0 \pm 0 \cdot 6 \\
2 \cdot 6 \pm 1 \cdot 0 \\
1 \cdot 7 \pm 0 \cdot 5 \star \star \star\end{array}$ \\
\hline
\end{tabular}

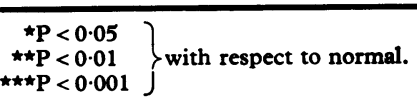

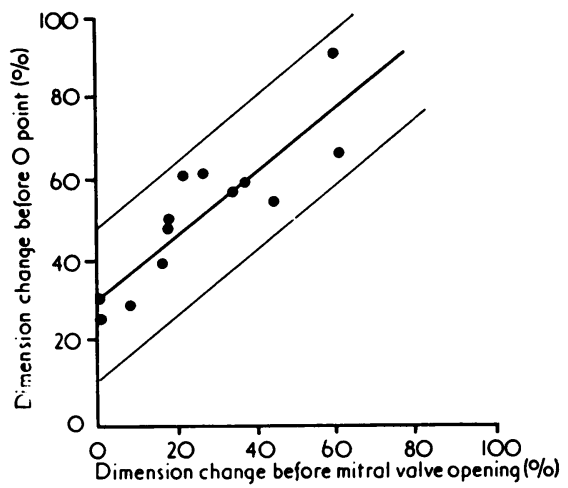

Fig. 10 Relation between dimension increase before the ' $O$ ' point and that before mitral valve opening expressed as a percentage of the total, in 13 patients with ischaemic heart disease. There is close correlation between the two.

and in man (Manolas et al., 1975) have indicated that the onset of left ventricular pressure rise at the start of systole is virtually synchronous with the corresponding event on the apex cardiogram, provided that measurements of pressure are made with a micromanometer and that a transducer of adequate frequency response is used to record the apex cardiogram. The relation between the nadir of the ventricular pressure trace and the ' $O$ ' point of the apex cardiogram is less certain. The two events are synchronous in dogs (Willems et al., 1971), but in man the apex cardiogram usually precedes the pressure by a small interval, though with considerable variation (Manolas et al., 1975). The apex cardiogram also shows a variable relation to valve movement in man, the ' $E$ ' point following aortic valve opening (Venco, unpublished observations) and the onset of ejection (Manolas et al., 1975), while the ' $O$ ' point is appreciably delayed with respect to mitral valve opening (Prewitt et al., 1975). Such studies have the limitation, for the present purpose, that only two points on each curve are compared, and it was to overcome this that the 
present method was used which allowed comparison throughout the periods of isovolumic contraction and early relaxation, and showed small, but consistent differences in timing between them. In all the patients studied, pressure events occurred significantly earlier than the corresponding events on the apex cardiogram. The mechanism for this difference was not clear. It was not the result of the time required for transmission by the transducer used for the apex cardiogram, as this was measured directly and found to be less than $1 \mathrm{~ms}$. It might have been caused in part by delay in transmission through the chest wall, but this cannot have been the sole explanation, particularly in early relaxation.

The apex cardiogram differs significantly from the pressure recording during ejection and also during diastole after the ' $O$ ' point. As has been pointed out, the exact configuration of the apex cardiogram during ejection was variable and not clearly associated with other clinical or haemodynamic evidence of left ventricular disease. During filling, discrepancies between the two recordings have considerable clinical significance, though the genesis of the rapid filling wave, the third heart sound point, and the ' $a$ ' wave are not clear. We conclude, therefore, that allowing for a small delay of 10 to $30 \mathrm{~ms}$, the apex cardiogram can be used to give the timing of the ventricular pressure trace during isovolumic contraction and early relaxation, but that during filling and ejection there are significant differences between the two.

In the normal subject, the timing of events on the apex cardiogram bears a close relation to those on the recording of the left ventricular dimension. During the upstroke, there is a slight reduction in left ventricular dimension, amounting to approximately 6 per cent of the total excursion, and at least part of this may be accounted for by the fact that the ' $E$ ' point of the apex cardiogram occurs slightly after the onset of ejection. During ejection, when the greatest change in dimension occurs, the amplitude of movement of the apex cardiogram is variable, and no consistent pattern emerged. However, at the start of ventricular relaxation, there was a sharp discontinuity in the apex cardiogram ('knee') with a further reduction in dimension. Finally, dimension again increased before the ' $O$ ' point, which has previously been shown to correlate more closely with peak rate of increase of dimension than with mitral valve opening (Prewitt et al., 1975). Nevertheless, overall changes in dimension during the downstroke of the apex cardiogram are small, so that during this period of the cardiac cycle, which had a mean duration of $120 \mathrm{~ms}$, septal and posterior wall echoes moved parallel to one another, usually in a posterior direction with respect to a transducer on the anterior chest wall. These relations between apex cardiogram and echo dimension were more clearly apparent when displayed as a loop, whose form, particularly during the periods of the upstroke and the downstroke, resembled those previously constructed between left ventricular pressure and dimension (Gibson and Brown, 1976).

The relations between echo dimension and apex cardiogram were also characteristic in patients with valvular heart disease. In mitral regurgitation, significant reduction in dimension occurred during the upstroke, reflecting backward movement of blood into the left atrium before aortic valve opening (Karliner, Bouchard, and Gault, 1971). Similarly, the abnormal increase in dimension before the ' $O$ ' point in aortic regurgitation is likely to be the result of early diastolic filling from the aortic root before mitral valve opening. Simultaneous recording of echocardiogram and apex cardiogram thus allows the abnormal timing of these changes in dimension to be established, thus giving information which is not available from the echocardiogram alone. These changes in dimension may be regarded as analogous to the changes in volume described by Rackley et al (1967) in valvular heart disease, and displayed in an exactly similar manner by constructing pressure-volume loops. This similarity depends on the fact that during the upstroke and downstroke, the apex cardiogram reflects the timing of the ventricular pressure pulse, and that contraction and relaxation in these patients with valvular heart disease is co-ordinated, so that the echo dimension can be taken as an index of the behaviour of the ventricle as a whole.

The abnormal relation between echo dimension and apex cardiogram in patients with ischaemic heart disease cannot be explained on these grounds, since none had significant valvular regurgitation. However, all had abnormal left ventricular angiograms, so that the timing of changes in ventricular dimension can no longer be taken as reflecting overall ventricular events. Rather, it seems likely that these abnormal changes in dimension were the result of regional disturbances of function. An increase or decrease in dimension during the upstroke of the apex cardiogram might thus reflect asynchronous onset of contraction (Karliner et al., 1971), with portions of myocardium developing tension early, moving inwards with corresponding outward movement elsewhere during the period of isovolumic contraction. It seems likely that both types of behaviour were observed in the present study. Similarly, during relaxation, the commonest abnormality was increased outward movement 
before the ' $O$ ' point of the apex cardiogram. This might have reflected an isovolumic shape change or abnormally rapid early diastolic filling. The former explanation seems more likely, since there was close correlation between these changes and the extent of outward wall movement before mitral valve opening, which is a direct measure of the severity of the isovolumic disturbance. Such changes have previously been documented angiographically (Altieri et al., 1973; Ruttley et al., 1974; Hamby et al., 1974; Wilson et al., 1975; Gibson et al., 1976), and by echocardiography (Upton et al., 1976).

This disturbed relation between echo dimension and apex cardiogram in patients with ischaemic heart disease and segmental abnormalities of left ventricular function suggests that the method might be used to detect incoordinate ventricular contraction and relaxation. In addition, the echo dimension itself can be used to give information about left ventricular cavity size and instantaneous rates of wall movement. These non-invasive methods, combined with relatively simple data handling techniques can thus be used to study three significant and separable aspects of left ventricular function. It is possible, therefore, that the present method may have applications in other clinical situations.

The computer equipment used in this study was provided by the DHSS as part of their experimental programme.

\section{References}

Altieri, P. I., Wilt, S. M., and Leighton, R. F. (1973). Left ventricular wall motion during the isovolumic relaxation period. Circulation, 48, 499.

Chaveau, A., and Marey, E. J. (1861). Determination graphique des rapports de la pulsation cardiaque avec les mouvements de l'oreillette et du ventricule, obtenue au moyen d'un appareil enregistreur. Gazette Médicale de Paris, 31, 675.

Gibson, D. G., and Brown, D. J. (1973). Measurement of instantaneous left ventricular dimension and filling rate in man, using echocardiography. British Heart fournal, 35, 1141.

Gibson, D. G., and Brown, D. J. (1976). Assessment of left ventricular systolic function in man from simultaneous echocardiographic and pressure measurements. British Heart fournal, 38, 8.

Gibson, D. G., Prewitt, T. A., and Brown, D. J. (1976). Echocardiographic assessment of left ventricular wall movement during isovolumic relaxation, and its relation to coronary artery disease. British Heart fournal, 38, 1010.

Hamby, R. I., Aintablian, A., Tabrah, F., Reddy, K., and Wisoff, G. (1974). Late systolic bulging of left ventricle in patients with angina pectoris. Chest, 65, 169.

Karliner, J. S., Bouchard, R. J., and Gault, J. H. (1971). Dimensional changes in the human left ventricle prior to aortic valve opening. A cineangiographic study in patients with and without left heart disease. Circulation, 44, 312.

Manolas, J., Rutishauser, W., Wirz, P., and Arbenz, U. (1975). Time relation between apex cardiogram and left ventricular events using simultaneous high-fidelity tracings in man. British Heart fournal, 37, 1263.

Prewitt, T., Gibson, D. G., Brown, D. J., and Sutton, G. (1975). The 'rapid filling wave' of the apex cardiogram. Its relation to echocardiographic and cineangiographic measurements of ventricular filling. British Heart fournal, 37, 1256.

Rackley, C. E., Behar, V. S., Whalen, R. E., and McIntosh, H. D. (1967). Biplane cineangiographic determination of left ventricular function: pressure-volume relationships. American Heart fournal, 74, 766.

Ruttley, M. S., Adams, D. F., Cohn, P. F., and Abrams, H. L. (1974). Shape and volume changes during 'isovolumetric relaxation' in normal and asynergic ventricles. Circulation, 50, 306.

Upton, M., Gibson, D. G., and Brown, D. J. (1976). Echocardiographic assessment of abnormal left ventricular relaxation in man. British Heart fournal, 38, 1001.

Willems, J. L., de Geest, H. D., and Kesteloot, H. (1971). On the value of apex cardiography for timing intracardiac events. American fournal of Cardiology, 28, 59.

Wilson, C. S., Krueger, S., Forker, A. D., and Weaver, W. F. (1975). Correlation between segmental early relaxation of the left ventricular wall and coronary occlusive disease. American Heart fournal, 89, 474.

Requests for reprints to Dr. D. G. Gibson, Cardiac Department, Brompton Hospital, Fulham Road, London SW3 6HP. 